\title{
Effects of Initial Porosity and Water Pressure on Seepage-Erosion Properties of Water Inrush in Completely Weathered Granite
}

\author{
Jinquan Liu, ${ }^{1,2}$ Weizhong Chen, ${ }^{3}$ Taogen Liu, ${ }^{4}$ Jianxin $Y u,{ }^{5}$ Jingliang Dong $\mathbb{D},{ }^{2}$ \\ and Wen Nie iD ${ }^{1}$ \\ ${ }^{1}$ Quanzhou Institute of Equipment Manufacturing, Haixi Institutes, Chinese Academy of Sciences, Quanzhou, Fujian 362000, China \\ ${ }^{2}$ School of Civil Engineering and Architecture, East China Jiaotong University, Nanchang, Jiangxi 330013, China \\ ${ }^{3}$ State Key Laboratory of Geomechanics and Geotechnical Engineering, Institute of Rock and Soil Mechanics, Chinese Academy of \\ Sciences, Wuhan, Hubei 430071, China \\ ${ }^{4}$ College of Civil Engineering \& Architecture, Nanchang Institute of Technology, Nanchang, Jiangxi 330013, China \\ ${ }^{5}$ School of Civil Engineering, Henan Polytechnic University, Jiaozuo, Henan 454000, China
}

Correspondence should be addressed to Jingliang Dong; 429146390@qq.com and Wen Nie; wen.nie@fjirsm.ac.cn

Received 16 March 2018; Accepted 22 April 2018; Published 16 August 2018

Academic Editor: Tommaso Caloiero

Copyright (C) 2018 Jinquan Liu et al. This is an open access article distributed under the Creative Commons Attribution License, which permits unrestricted use, distribution, and reproduction in any medium, provided the original work is properly cited.

In order to investigate the water inrush mechanism in completely weathered granite, a large-scale triaxial testing system is designed and manufactured, which can induce the mass transfer and monitor the flow properties. Using this system, the effects of water pressure and initial porosity on the mass transfer and flow properties were determined, and the relative critical conditions for water inrush were proposed. The results indicate that (1) the particle transfer could cause an increase in porosity, permeability, and water inflow, which is the essential reason for water inrush in completely weathered granite. (2) Due to the effect of particle transfer, the flow properties may change from a Darcy to a non-Darcy flow, which is a key signal for water inrush. (3) With the increase of water pressure, the mass transfer, permeability, and water inflow increased gradually, and a critical value $(p=0.6 \mathrm{MPa})$ that caused the water inrush was obtained. Furthermore, with the decrease of initial porosity, the mass transfer and flow properties were suppressed rapidly, and a critical porosity (0.23) to anti-inrush was observed. The results obtained can provide an important reference for understanding the mechanism, forecasting the risk, and taking the effective control measures for water inrush.

\section{Introduction}

In recent years, a large number of tunnels have been constructed in unfavorable geology such as completely weathered granite, karst, and fault [1-4], causing various challenges to the geotechnical engineers, for example, collapse [5], land subsidence [6], groundwater inflow [7, 8], and total environmental hazards [9]. The completely weathered granite, one of the typical unfavorable geologies, is widely distributed in subtropical, tropical, and humid temperature zones [10-12]. This material has the properties of weak water stability, low strength, and strong disintegration [13]. Under the effect of water, this material erodes rapidly and becomes weak and soil-like as observed in recent field investigations ([1]; $[14,15])$. Therefore, tunnel construction in this condition often faces a great risk of water and mud inrush $[2,8,16]$, which has become a difficult issue for the tunnel engineers.

In order to analyze and forecast the water inrush, many scholars proposed various simplified methods, such as water inrush coefficient $[17,18]$, underlying belt theory [19], and key strata model [20]. However, these methods oversimplify the geological conditions and cannot accurately predict the probability of water inrush. Considering the flow properties, some scholars proposed the flow stress coupling models which the flow equation adopted a Darcy or modified Darcy's equation [21-23] and many other analytical and semianalytical solution to predict the water inflow and water inrush $([7,18,24])$; however, these models do not consider the erosion property and nonlinear flow, which cannot reflect 


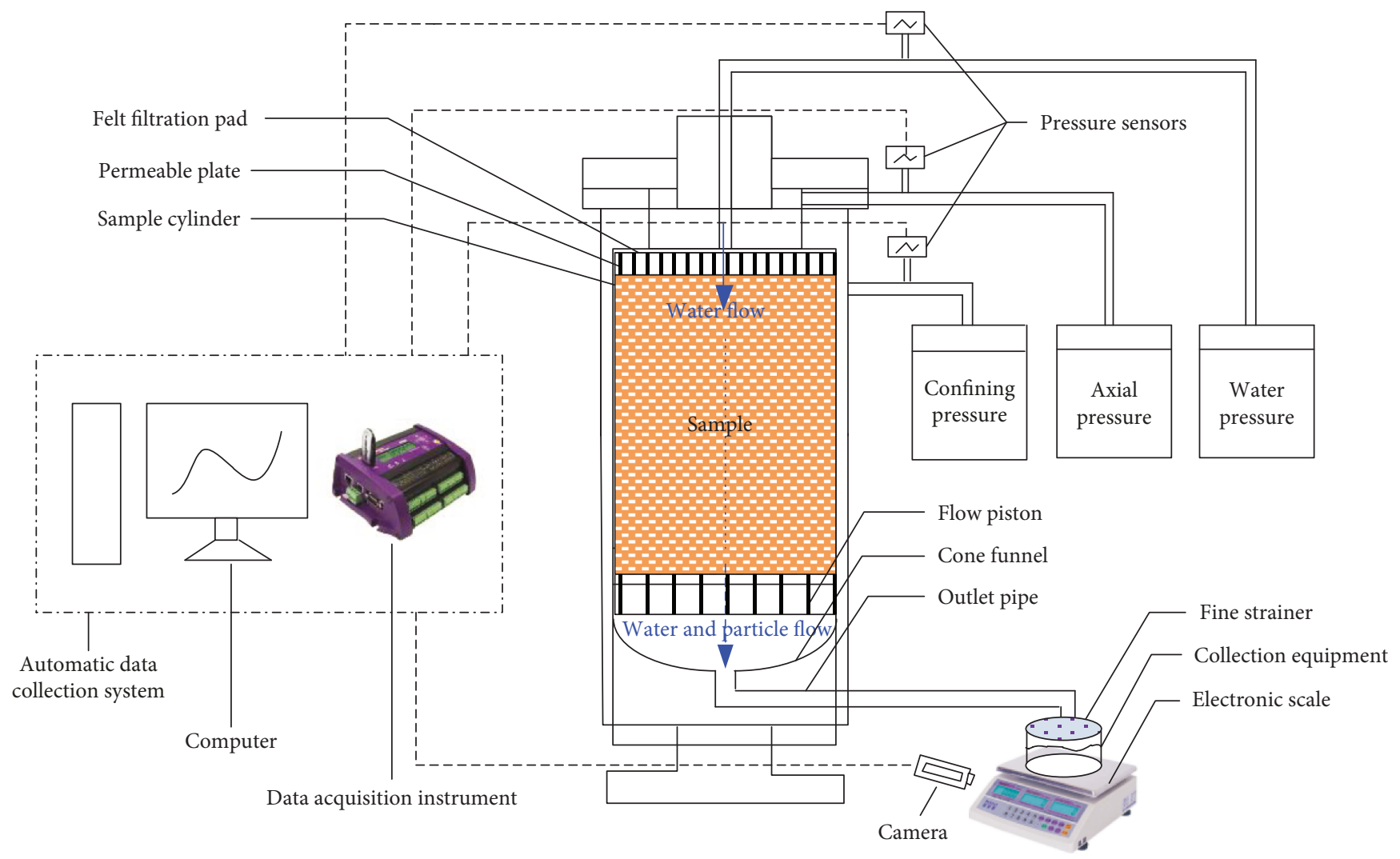

Figure 1: Large-scale triaxial testing system.

the mechanism of water inrush in completely weathered granite. Furthermore, many research results showed that lithology, water pressure, and pore structure are the key factors causing water inrush [25-27]. For example, [25] analyzed the water inrush of 12 coal seam floors and found that water inrush is more prone to occur with water pressure increasing. Walsh [28] and Wang et al. [29] studied the permeability under different water pressures and confining pressures. Moreover, many researches showed that the critical conditions existed for water inrush, such as water pressure and excavation thickness $[4,30]$.

In view of this, the objectives of this study are to investigate the mass transfer and nonlinear seepage properties of completely weathered granite and to quantify the impacts of water pressure and initial porosity on the water inrush evolution. To do this, we designed a new testing system that can simulate the properties of particle transfer and stress conditions, investigated the seepage-erosion properties under different water pressures and initial porosities, and finally proposed the critical relative conditions for water inrush.

\section{Experimental System and Procedure}

2.1. Testing System. As shown in Figure 1, a self-designed large-scale triaxial testing system is made up of four parties: a pressure control system, a particle transfer permeability testing system, an automatic data collection equipment, and a water and mud collection equipment. Figure 1 illustrates the system connections and principle.
The pressure control system is used to provide a constant stability axial pressure, confining pressure, and water pressure by three independent but the same structure pressure systems, composed of a hydraulic cylinder, gas pump, relief valve, and water pump. In the test, after using the water pump to fill the hydraulic cylinder with water, the gas pump is employed to provide a constant speed water inflow into the permeability system.

The most important part of this system is the particle transfer permeability testing system, which is mainly composed of a sample cylinder, permeable plate, flow piston, and cone funnel. A sample cylinder, with a maximum diameter and height of $100 \mathrm{~mm}$ and $300 \mathrm{~mm}$, respectively, is used to place the test sample. The permeable plate design containing numerous "uniform and dense" holes can ensure that the water flows evenly, and the felt filtration pad can prevent the pores of the permeable plate from being blocked by the sample particles. The uniform "13mm-diameter hole" flow piston will cause some particles from being flown away; the remaining particles pass through the cone funnel and can be collected by an outlet pipe and collection equipment.

The automatic data collection equipment includes pressure sensors, a camera for monitoring the flow rate, a computer, and a data acquisition instrument, which are used to collect the test pressures and flow rate (water flow velocity and particle transfer rate). The water and mud collection equipment includes a fine strainer and a collection container, which are used to filter and collect the particles and water. 
TABle 1: Physical and mechanical parameters of completely weathered granite.

\begin{tabular}{lccccc}
\hline Natural density $/ \mathrm{g} \mathrm{cm}^{-3}$ & Natural moisture $/ \%$ & Porosity & Permeability coefficient $/ \mathrm{cm} \mathrm{s}^{-1}$ & Cohesion $c_{\text {uu }} / \mathrm{kPa}$ & Internal friction angle $\Phi_{\mathrm{uu}} /^{\circ}$ \\
\hline 1.9 & 17 & 0.36 & $4.05 \times 10^{-4}$ & 60.2 & 1.9 \\
\hline
\end{tabular}

TABLE 2: Test scheme.

\begin{tabular}{|c|c|c|c|c|c|c|c|c|}
\hline \multirow{2}{*}{ Number } & \multirow{2}{*}{ Water pressure $(\mathrm{MPa})$} & \multirow{2}{*}{ Initial porosity } & \multirow{2}{*}{ Total mass $m_{\mathrm{t}}(\mathrm{g})$} & \multicolumn{5}{|c|}{ Weight to each particle size $(\mathrm{g})$} \\
\hline & & & & $m_{(0-0.25 \mathrm{~mm})}$ & $m_{(0.25-2 \mathrm{~mm})}$ & $m_{(2-3 \mathrm{~mm})}$ & $m_{(3-5 \mathrm{~mm})}$ & $m_{(5-10 \mathrm{~mm})}$ \\
\hline 1 & 0.2 & 0.36 & 3233 & 628.5 & 885.1 & 569.6 & 430.9 & 718.8 \\
\hline 2 & 0.4 & & & 628.5 & 885.1 & 569.6 & 430.9 & 718.8 \\
\hline 3 & 0.6 & & & 628.5 & 885.1 & 569.6 & 430.9 & 718.8 \\
\hline 4 & 0.6 & 0.23 & 3890 & 756.2 & 1064.9 & 685.3 & 518.4 & 864.8 \\
\hline 5 & & 0.30 & 3536 & 687.5 & 968.1 & 623.0 & 471.3 & 786.1 \\
\hline 6 & & 0.36 & 3233 & 628.5 & 885.1 & 569.6 & 430.9 & 718.8 \\
\hline
\end{tabular}

\subsection{Testing Design and Procedure}

2.2.1. Testing Sample and Design. The samples used in the test were selected from approximately -100 strata in a typical weathered granite tunnel engineering, in Junchang tunnel in Guangxi Province of China [16]. Tests by the X-ray diffraction analysis showed that the sample minerals are quartz, illite, and kaolinite with a mass proportion of $75.2 \%, 19.3 \%$, and $5.5 \%$, respectively. Table 1 presents the basic physical and mechanical parameters of completely weathered granite.

According to practical engineering, the axial pressure, confining pressure, and water pressure tests were $2 \mathrm{MPa}$, $1 \mathrm{MPa}$, and $0.6 \mathrm{MPa}$, respectively. In the test, the coarse particles $(>10 \mathrm{~mm})$ were screened out, and the soil particles are classified into the following five groups based on the particle sizes using a screening test sieve machine: $0-0.25 \mathrm{~mm}$, $0.25-2 \mathrm{~mm}, 2-3 \mathrm{~mm}, 3-5 \mathrm{~mm}$, and 5-10 mm. The samples used include the above five group particle sizes with the weight designed as shown in Table 2. Furthermore, the designed sample height and diameter were $200 \mathrm{~mm}$ and $100 \mathrm{~mm}$, respectively.

2.2.2. Testing Method and Procedure. The samples are required to be completely saturated by water before each experiment. The testing fluid is water with density= $1000 \mathrm{~kg} / \mathrm{m}^{3}$ and kinetic viscosity $=1.01 \times 10^{-3} \mathrm{~Pa} \cdot \mathrm{s}$ at the standard state. To obtain stable readings, measurements of the pressure and flow rate are performed after the axial pressure and confining pressure are maintained at a fixed level.

The test steps are as follows:

(1) Fill the sample: first, weigh the sample. Place and compact the sample into the sample cylinder as layers and then install the permeable plate and assemble the test system.

(2) Saturate the sample: saturate the sample with a water injection using the water pressure control system and then measure the initial permeability.
(3) Apply the axial and confining load: apply the axial and confining load to the sample gradually, reach the desired values, and then keep the loads steady until the test is completed.

(4) Apply the water pressure to the sample and collect the test data: first, apply the desired water pressure to the sample gradually and start the penetration test. Then immediately monitor the test data (pressure and flow velocity) and collect the eroded particles and water flow every $30 \mathrm{~s}$.

Figure 2 illustrates the entire experimental procedure. The criteria for the test termination are that the particles are not eroded away and the flow water is clear.

2.3. Test Parameter Measurement and Calculation Principle. During water flow in a completely weathered granite, the particles will be washed away because of the effect of water pressure, which will cause an increase in the porosity and permeability and thus induce an increase in the water inflow. Moreover, the flow properties may change from a Darcy flow to a non-Darcy flow, with a consistent increase in particle loss. Therefore, based on the mass transfer, the porosity, permeability, water inflow evolution rate with time, a nonDarcy flow, and water inrush can be determined.

2.3.1. Mass of Particle Transfer. In the tests, particles are collected every $30 \mathrm{~s}(\Delta t)$, and the particle mass transferred in each $\Delta t$ is $\Delta m_{1}, \Delta m_{2}, \ldots, \Delta m_{m}$.

The total particle mass transfer for $t_{i}=\Delta t_{1}+\Delta t_{2}+\cdots+$ $\Delta t_{i}=i \Delta t(i=1,2, \ldots, m)$ is $m_{m}$.

$$
m_{i}=\Delta m_{1}+\Delta m_{2}+\cdots+\Delta m_{i} \quad(i=1,2, \ldots, m)
$$

2.3.2. Porosity Evolution. The sample porosity will increase with the particle transfer. Porosity $\varphi_{i}$ in time $\left(t_{i-1}, t_{i}\right)$ is

$\varphi_{i}=\varphi_{0}+\frac{1}{\pi a^{2} h_{i} \rho_{\mathrm{s}}}\left(\Delta m_{1}+\Delta m_{2}+\cdots+\Delta m_{i}\right) \quad(i=1,2, \ldots, m)$ 


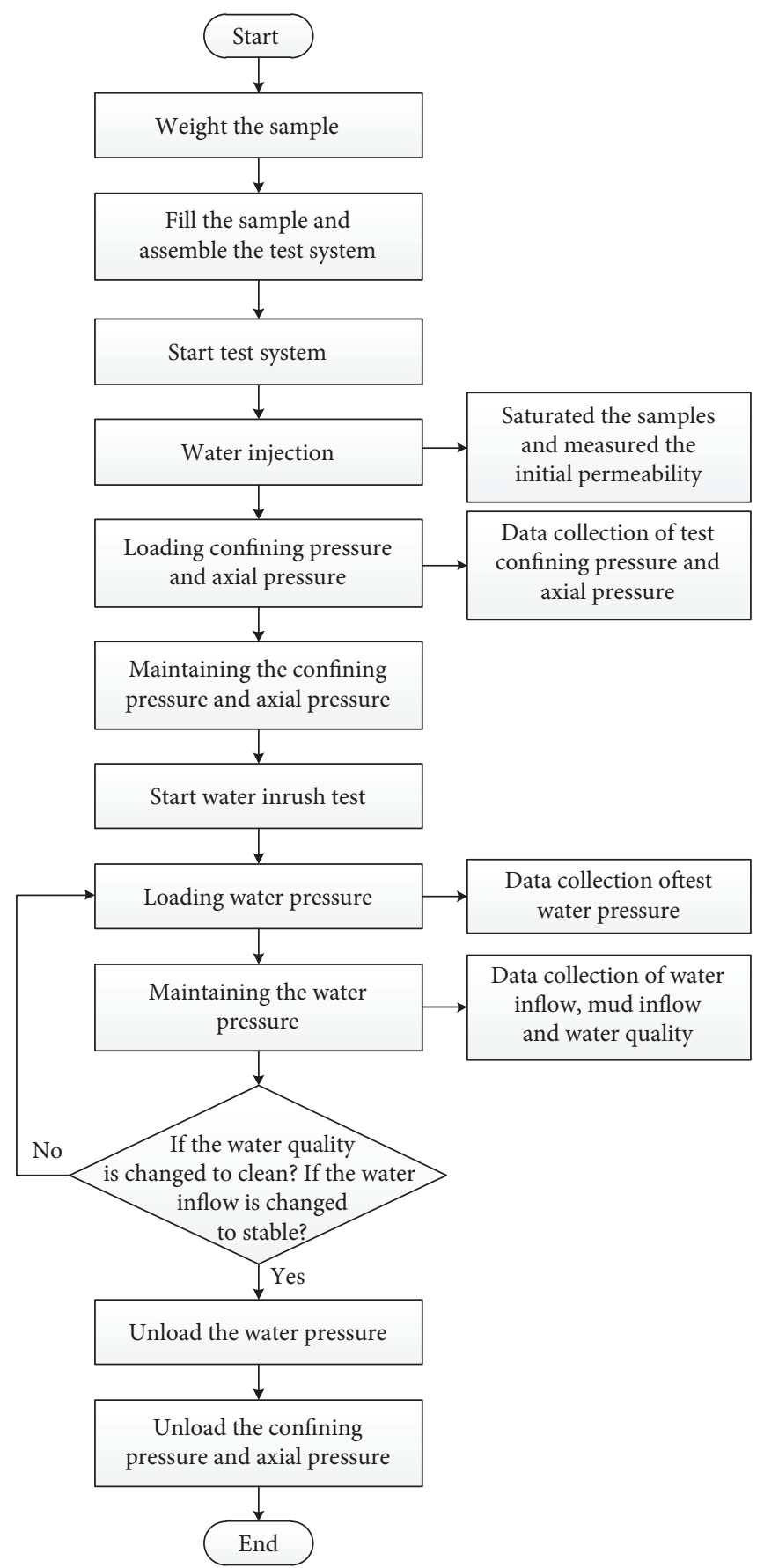

FIGURE 2: Experimental procedure of completely weathered granite.

where $a$ is the sample radius; $\rho_{\mathrm{s}}$ is the mass density of the grain. $h_{i}$ is the real-time sample height, which is calculated according to the mass transfer. To calculate the real-time height, it is assumed that the mass transfer is approximately from the bottom sample particles, leading to a change in the sample height. The expression of $h_{i}$ is as follows:

$$
h_{i}=h_{0}-\frac{1}{\pi a^{2} \rho_{\mathrm{s}}}\left(\Delta m_{1}+\Delta m_{2}+\cdots+\Delta m_{i}\right) \quad(i=1,2, \ldots, m) \text {. }
$$

2.3.3. Permeability Evolution and Non-Darcy Approach. Under the effect of particle transfer, the sample permeability will increase and may cause the flow pattern to change from a Darcy to a non-Darcy flow. For a completely weathered granite, the Reynolds number ( $\mathrm{Re})$ is defined as follows:

$$
\operatorname{Re}=\frac{\rho_{\mathrm{f}} v d_{\mathrm{p}}}{\mu \varphi}
$$

where $\rho_{\mathrm{f}}$ is the water density, $v$ is the average water flow velocity, $d_{\mathrm{p}}$ is a grain diameter greater than that of $10 \%$ of 
TABLe 3: Mass transfer amounts with time to each sample (g) (partial results).

\begin{tabular}{lccccccccccccc}
\hline \multirow{2}{*}{ Number } & \multirow{2}{*}{ Water pressure (MPa) } & \multirow{2}{*}{ Initial porosity } & 0 & 5 & 10 & 20 & 30 & 40 & 50 & 60 & 90 & 120 \\
\hline 1 & 0.2 & 0.36 & 0 & 8.8 & 17.4 & 30.8 & 45.0 & 54.8 & & & \\
2 & 0.4 & & 0 & 20.0 & 34.9 & 66.5 & 85.0 & 92.3 & 116.1 & 145.7 & \\
3 & 0.6 & & 0 & 8.4 & 25.5 & 76.7 & 129.2 & 205.7 & 276.9 & 287.9 & 345.6 & \\
4 & 0.6 & 0.23 & 0 & 13.0 & 22.5 & 39.1 & 67.9 & 86.7 & 99.4 & 101.7 & 113.2 & 120.3 \\
5 & & 0.30 & 0 & 38.3 & 62.9 & 88.1 & 116.8 & 137.3 & 149.0 & 164.4 & 240.2 & 259.9 \\
6 & & 0.36 & 0 & 8.4 & 25.5 & 76.7 & 129.2 & 205.7 & 276.9 & 287.9 & 345.6 & \\
\hline
\end{tabular}

the particles by weight, and $\mu$ is the kinetic viscosity of the water.

Various studies have shown that the critical Reynolds number for a flow between a Darcy and a non-Darcy flow is 10 , and that for different porous media, this limit is slightly different $[31,32]$.

When $\operatorname{Re} \leq 10$, the flow satisfies Darcy's law as follows:

$$
v=-\frac{k}{\mu}\left(\nabla p+\rho_{\mathrm{f}} g \nabla z\right),
$$

where $k$ is the sample absolute permeability, $\nabla p$ is the pore pressure gradient, $g$ is the gravitational acceleration, and $z$ is the vertical axis passing through the center of the sample and its direction is upward.

Compared with the water pressure, gravity can be ignored owing to the relatively small sample size, and Darcy's law for a one-dimensional axial flow can be simplified as follows:

$$
v=-\frac{k}{\mu} \nabla p
$$

where $v$ is calculated by water inflow $Q$.

$$
v=\frac{Q}{\pi a^{2}} .
$$

In the test, the upstream end of the sample was connected to the water pressure system, which could automatically record the change in the pore pressure over time. The inlet boundary at pore pressure $p_{1}$ was assumed to have a steady value of $p$ as tested and designed, whereas the outlet boundary was exposed to the atmosphere, causing pore pressure $p_{2}$ to be zero. Assuming that the water pressure is uniformly distributed, the pressure gradient can be simplified as follows:

$$
\nabla p=\frac{\partial p}{\partial z}=-\frac{p_{2}-p_{1}}{h_{i}}=-\frac{p}{h_{i}} .
$$

Therefore, combining (5), (6), (7), and (8), permeability $k_{i}$ at moment $t_{i}$ can be obtained for the Darcy flow.

$$
k_{i}=\frac{Q \mu}{\pi a^{2}} \frac{h_{i}}{p} \quad(i=1,2, \ldots, m) .
$$

When $\operatorname{Re}>10$, the flow rate will increase rapidly and the flow process will enter the non-Darcy stage. The Forchheimer equation [33] as given below, considering the inertia force of the fluid flow, is more suitable for depicting the non-Darcy flow.

$$
-\frac{\partial p}{\partial z}=\frac{\mu}{k} v+\rho_{\mathrm{f}} \beta v^{2}
$$

where $\beta$ is the coefficient of the non-Darcy flow.

Considering the permeability to be continuously changing in the evolution process, to obtain the time evolution of permeability, permeability $k_{i}$ at moment $t_{i}$ was approximately calculated by the average permeability value at time $\left(t_{i}-t_{i+1}\right)$. Therefore, the permeability for the non-Darcy flow can be obtained by a second-order polynomial method.

$$
k_{i}=\frac{\mu v_{i} v_{i+1}\left(v_{i+1}-v_{i}\right)}{\left(v_{i+1}{ }^{2} h_{i}-v_{i}^{2} h_{i+1}\right) p} h_{i} h_{i+1} \quad(i=1,2, \ldots, m),
$$

where $v_{i}$ is the flow velocity at moment $t_{i}$.

2.4. Fluidized Grain Concentration. Fluidized grain concentration $c$ refers to the concentration of grains dissolved in the fluid and is defined as follows:

$$
c=\frac{\Delta m_{i}}{\rho_{\mathrm{f}} \Delta Q_{i}+\Delta m_{i}} \quad(i=1,2, \ldots, m),
$$

where $\Delta Q_{m}$ is the water inflow in time $\Delta t$.

\section{Test Results and Discussion}

In order to investigate the impact of water pressure and porosity on seepage-erosion properties of completely weathered granite and to propose the respective critical conditions for water inrush, a series of tests consider the last factors as water pressure and initial porosity were conducted, and the mass transfer, porosity, water inflow, permeability, and the flow pattern through the tests were also monitored. Specifically, first, the tests under different water pressures were conducted to investigate the critical water pressure for water inrush, and then the variable initial porosity based on the critical water pressure was conducted to investigate the critical porosity.

The transferred particles are collected for every 30 seconds; according to (1), the mass transfer for $t_{i}(i=1$, $2, \ldots, n)$ can be obtained as shown in Table 3. Meanwhile, according to (2), the porosity to time $t_{i}$ can be calculated as shown in Table 4 . By data collection of water inflow and combining (4), (9), and (11), the Reynolds number, 
TABLe 4: Porosity with time to each sample (partial results).

\begin{tabular}{lcccccccccccc}
\hline \multirow{2}{*}{ Number } & \multirow{2}{*}{ Water pressure (MPa) } & Initial porosity & 0 & 5 & 10 & 20 & 30 & 40 & 50 & 60 & 90 & 120 \\
\hline 1 & 0.2 & 0.36 & 0.36 & 0.36 & 0.36 & 0.37 & 0.37 & 0.37 & & \\
2 & 0.4 & & 0.36 & 0.36 & 0.37 & 0.38 & 0.38 & 0.38 & 0.39 & 0.39 & \\
3 & 0.6 & & 0.36 & 0.36 & 0.37 & 0.38 & 0.39 & 0.41 & 0.43 & 0.43 & 0.44 & \\
4 & 0.6 & 0.23 & 0.23 & 0.23 & 0.24 & 0.24 & 0.25 & 0.25 & 0.25 & 0.25 & 0.26 & 0.26 \\
5 & & 0.30 & 0.30 & 0.31 & 0.32 & 0.32 & 0.33 & 0.33 & 0.34 & 0.34 & 0.36 & 0.36 \\
6 & & 0.36 & 0.36 & 0.36 & 0.37 & 0.38 & 0.39 & 0.41 & 0.43 & 0.43 & 0.44 & \\
\hline
\end{tabular}

TABLE 5: Reynolds number with time to each sample (partial results).

\begin{tabular}{lccccccccccccc}
\hline \multirow{2}{*}{ Number } & \multirow{2}{*}{ Water pressure (MPa) } & \multirow{2}{*}{ Initial porosity } & 0 & 5 & 10 & 20 & 30 & 40 & 50 & 60 & 90 & 120 \\
\hline 1 & & 0.36 & 0 & 0.07 & 0.11 & 0.07 & 0.07 & 0.10 & & & \\
2 & 0.2 & & 0 & 1.70 & 2.44 & 2.32 & 2.34 & 2.42 & 3.50 & 3.94 \\
3 & 0.4 & & 0 & 0.74 & 2.11 & 6.84 & 8.65 & 12.16 & 13.00 & 10.38 & 11.81 \\
4 & 0.6 & 0.23 & 0 & 0.21 & 0.12 & 0.13 & 0.15 & 0.14 & 0.16 & 0.16 & 0.16 & 0.16 \\
5 & 0.6 & 0.30 & 0 & 1.97 & 1.36 & 1.20 & 1.75 & 2.51 & 2.50 & 2.98 & 1.54 & 1.87 \\
6 & & 0.36 & 0 & 0.74 & 2.11 & 6.84 & 8.65 & 12.16 & 13.00 & 10.38 & 11.81 & \\
\hline
\end{tabular}

TABle 6: Permeability with time to each sample (unit: $e-12 \mathrm{~m}^{2}$ ) (partial results).

\begin{tabular}{lcccccccccccc}
\hline \multirow{2}{*}{ Number } & \multirow{2}{*}{ Water pressure (MPa) } & Initial porosity & 0 & 5 & 10 & 20 & 30 & 40 & 50 & 60 & 90 & 120 \\
\hline 1 & 0.2 & 0.36 & 0.5 & 4.1 & 5.5 & 6.2 & 6.4 & 6.2 & & \\
2 & 0.4 & & 0.5 & 3.4 & 4.4 & 4.5 & 4.7 & 4.3 & 6.5 & 7.5 & \\
3 & 0.6 & & 0.5 & 1.0 & 1.8 & 8.4 & 12.1 & 14.9 & 14.6 & 14.1 & 15.6 & \\
4 & 0.6 & 0.23 & 0.3 & 4.6 & 3.1 & 2.5 & 3.3 & 3.3 & 3.9 & 4.0 & 4.1 & 5.2 \\
5 & & 0.30 & 0.4 & 2.4 & 1.8 & 1.3 & 1.7 & 2.7 & 2.8 & 3.5 & 2.0 & 2.0 \\
6 & & 0.36 & 0.5 & 1.0 & 1.8 & 8.4 & 12.1 & 14.9 & 14.6 & 14.1 & 15.6 \\
\hline
\end{tabular}

permeability can be obtained, as shown in Tables 5 and 6 . All of the data are drawn in Figures 3-13.

\subsection{Effect of Water Pressure on Seepage-Erosion Properties}

3.1.1. Mass Transfer Properties under Different Water Pressures. According to the field investigation, large variations of water pressure exist in the weathered zone of Junchang tunnel, which range from 0.2 to $1.5 \mathrm{MPa}$. Therefore, tests of different water pressures but the same porosity (0.36) were carried out to study the critical water pressure for water inrush, and the designed water pressures were increased from $0.2 \mathrm{MPa}$ to critical value by every $0.2 \mathrm{MPa}$.

As shown in Figure 3, the weight of particle transfer $m$ increases with time passes and meets maximum finally. For $p=0.2 \mathrm{MPa}$, the maximum mass transfer is $54.84 \mathrm{~g}$, reaching $1.7 \%$ of the total mass, and the average mass rate (curve slope) is $1.37 \mathrm{~g} / \mathrm{min}$. When $p=0.4 \mathrm{MPa}$, the mass transfer and average mass rate increase to $190.42 \mathrm{~g}$ and $2.5 \mathrm{~g} / \mathrm{min}$, respectively. With the pressure increases to $0.6 \mathrm{MPa}$, the mass transfer and average mass rate significantly increase to $354.22 \mathrm{~g}$ and $5.37 \mathrm{~g} / \mathrm{min}$, respectively. This is mainly because of higher water pressure has higher water seepage ability. The mass transfer is lower than $5 \%$ of sample total mass when $p \leq 0.4 \mathrm{MPa}$; however, when $p=0.6 \mathrm{MPa}$, the mass transfer reaches the $11 \%$ of the total mass, indicating that a large amount of particles has been eroded.

Figure 4 shows the porosity increases with water pressure; the finial porosity for $p=0.2,0.4$, and $0.6 \mathrm{MPa}$ is 0.37 , 0.40 , and 0.44 , a $2.8 \%, 11.1 \%$, and $22.2 \%$ increase of initial porosity, respectively. It can be obtained that the evolution of porosity is consistent with the mass transfer.

Furthermore, the fluidized grain concentration, which can reflect the effect of the mass generation and water seepage process, can be divided into two stages, namely, increased at first and decreased at last, as shown in Figure 5. At the first stage, owing to the high content of fine particles and low permeability, numerous particles will be generated and cannot be transferred, resulting in an increase in fluidized grain concentration. In contrast, the concentration will 


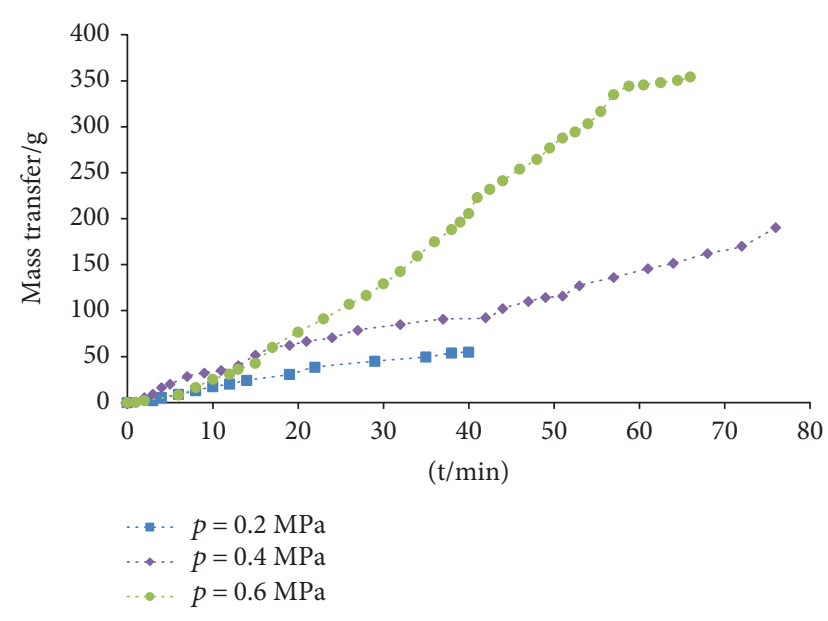

FIgURE 3: Mass transfer for different water pressures.

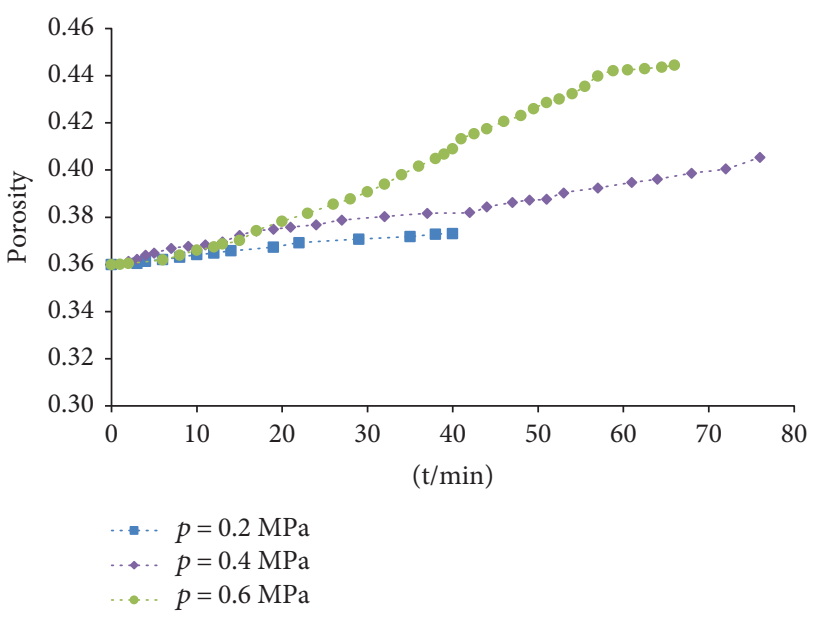

FIGURE 4: Time evolution of porosity for different water pressures.

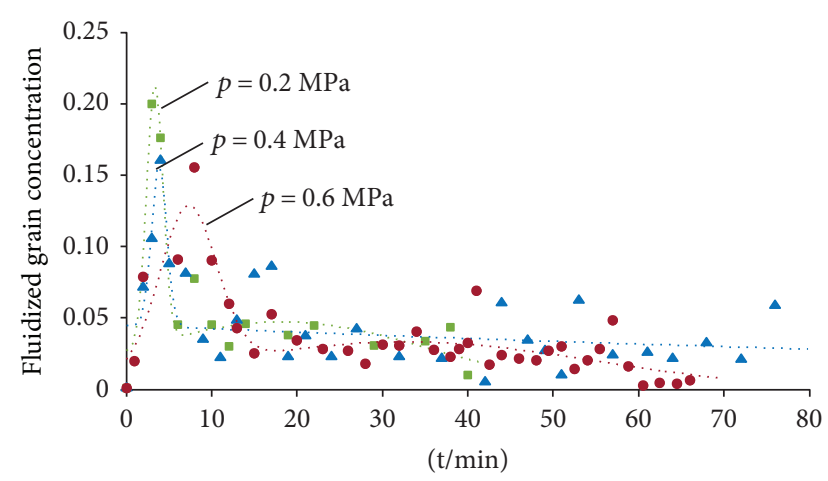

Figure 5: Time evolution of fluidize grain concentration for different water pressures.

decrease with the increase in seepage ability along with the decrease in mass generation in the second stage. From Figure 5, the peak value of concentration decreases with the increase in water pressure, and this is mainly because of the higher water pressure has higher water seepage ability,

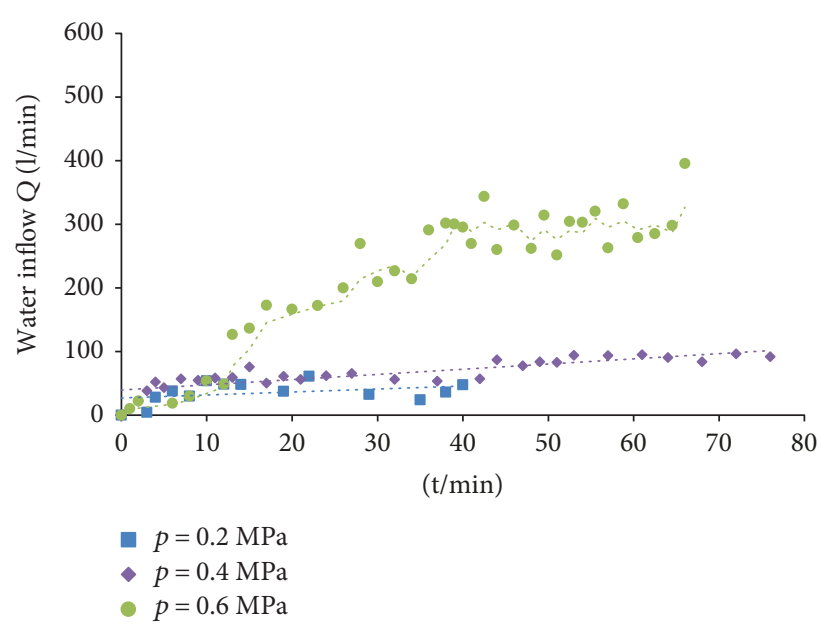

Figure 6: Time evolution of water inflow for different water pressures.

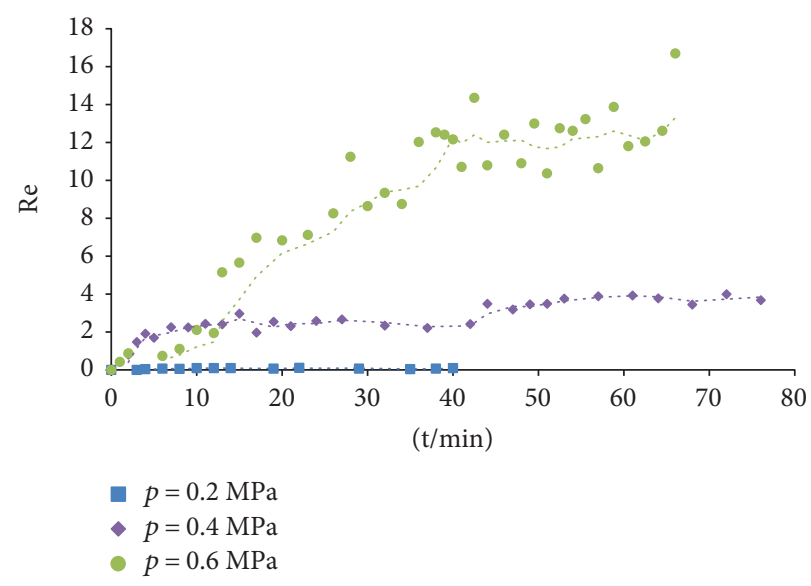

FIgURE 7: Time evolution of Reynolds number for different water pressures.

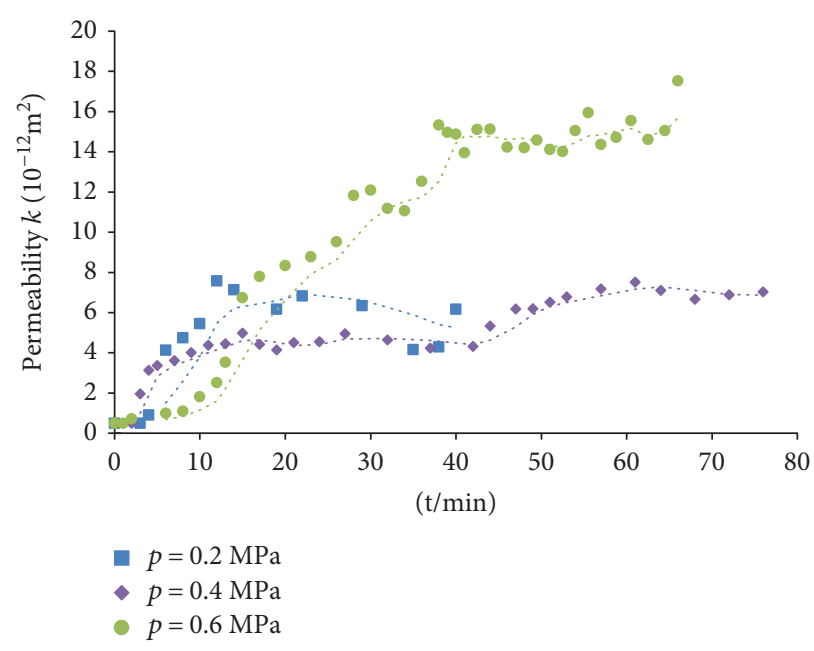

Figure 8: Time evolution of permeability for different water pressures. 


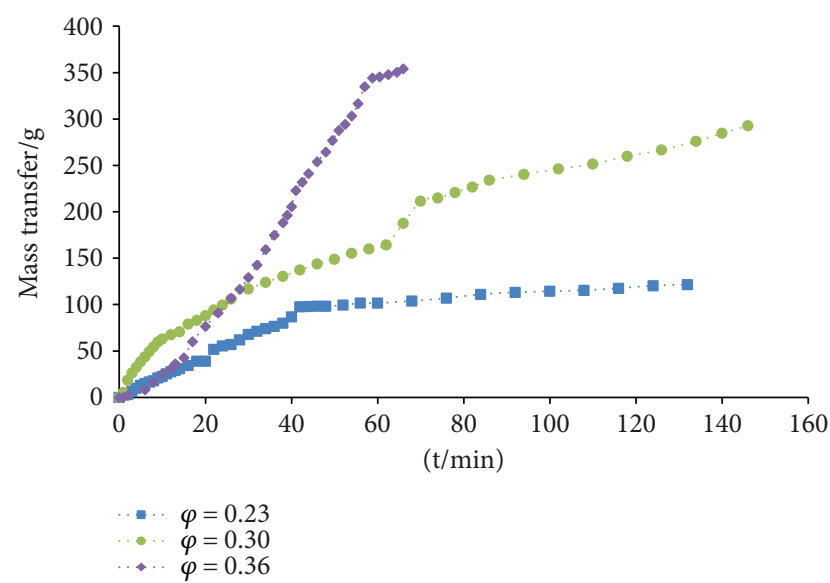

FIgURE 9: Time evolution of mass transfer for different initial porosities.

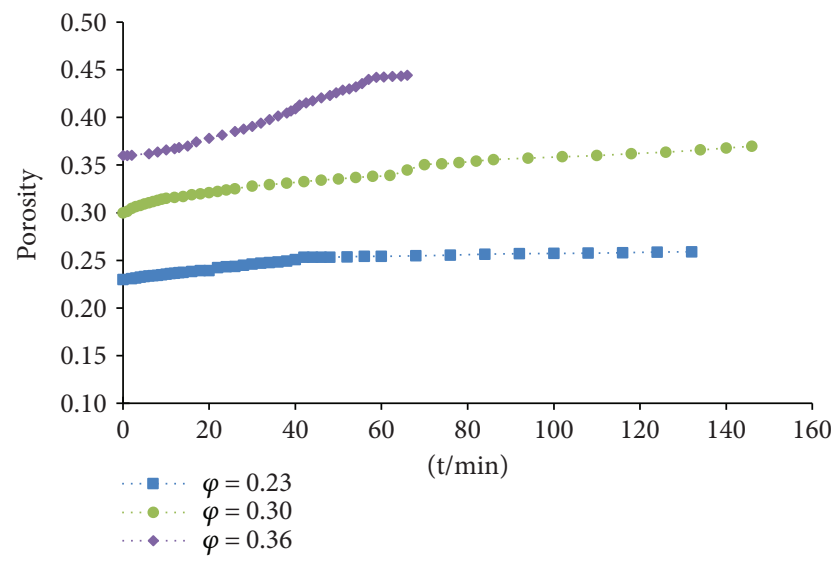

FIGURE 10: Time evolution of porosity for different initial porosities.

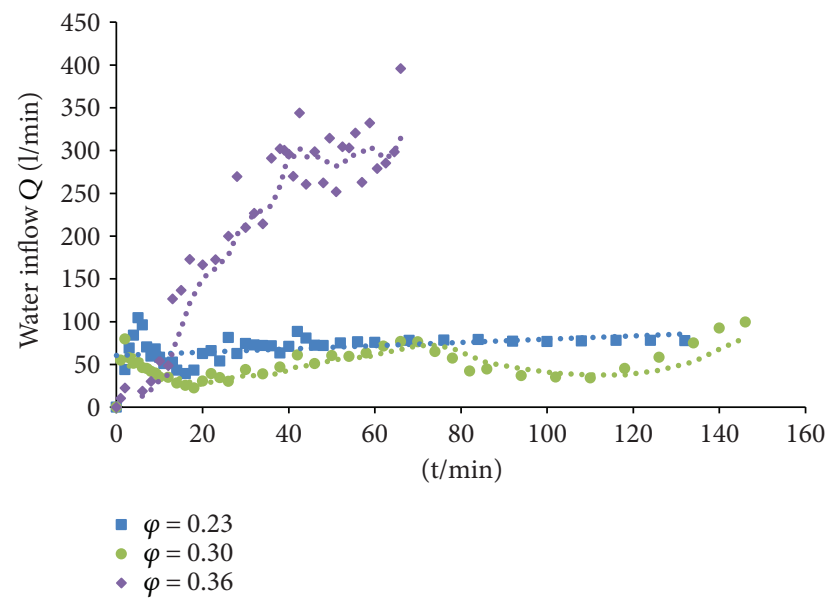

FIgURE 11: Time evolution of water inflow for different initial porosities.

resulting in the particle transfer that is faster than mass generation, which indicates that a water inrush channel is easier to form.

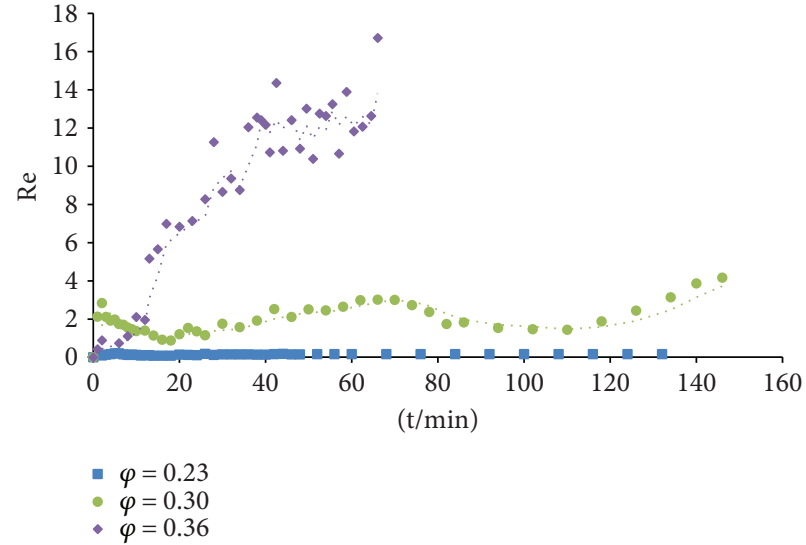

FIgURE 12: Time evolution of Reynolds number for different initial porosities.

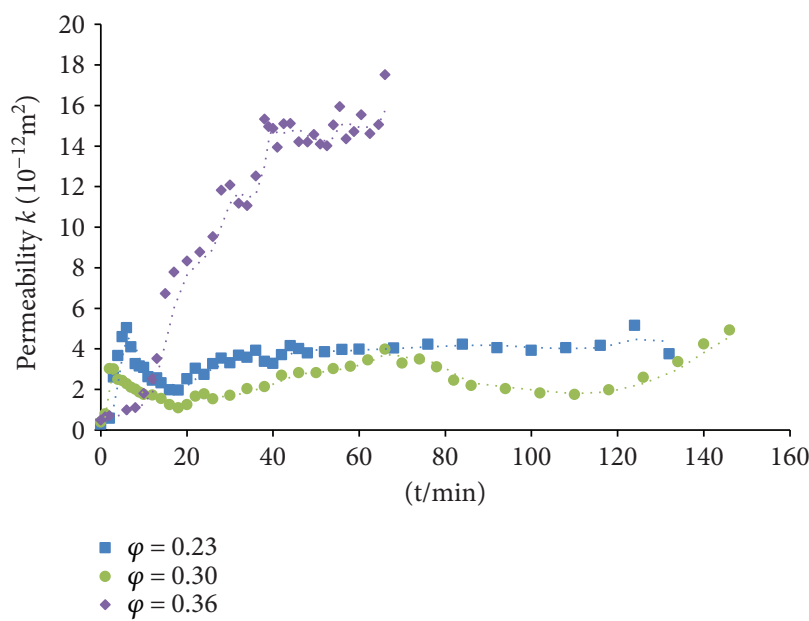

FIgUre 13: Time evolution of permeability for different initial porosities.

Therefore, it is reasonable to conclude that the particle transfer is the key factor determining the porosity and flow properties such as permeability and flow pattern, as discussed in the following sections. In addition, when $p \geq 0.6 \mathrm{MPa}$, the mass transfer and porosity increase rapidly in a short time, indicating that the risk of water inrush is more serious.

3.1.2. Seepage Properties under Different Water Pressures. Water inflow, the key factor in evaluating the risk of water inrush, is shown in Figure 6. The water inflow increases with the increasing water pressure; the increase for $p \leq 0.4 \mathrm{MPa}$ is linear and smaller, and the maximum value is $91.89 \mathrm{ml} / \mathrm{min}$. In comparison, the water inflow when $p=0.6 \mathrm{MPa}$ is as high as $395.84 \mathrm{ml} / \mathrm{min}$, larger by over 4.3 times that when $p \leq 0.4$ $\mathrm{MPa}$. This indicates that there exists a critical water pressure $(0.6 \mathrm{MPa})$ to induce the significant increase of water inflow.

By collecting water inflow data and using (4), the time evolution of the Reynolds number ( $\mathrm{Re}$ ) to variable water pressure can be obtained, which is shown in Figure 7. As stated by various scholars, for a flow between a Darcy and a 
non-Darcy, the critical Reynolds number is 10 [31, 32]. Therefore, it can be observed from the figure that in the entire time, Re is linearly evolving, and the maximum Re is 3.67 , which is much less than 10 when $p<0.6 \mathrm{MPa}$, indicating that the flow is a Darcy flow. However, when $p=0.6 \mathrm{M}$ $\mathrm{Pa}$, Re increases rapidly, exceeding 10 in $28 \mathrm{~min}$, and a maximum Re of 16.7 is attained, indicating that the flow pattern has changed from a Darcy to a non-Darcy flow after 28 min of evolution (see Table 7).

By collecting water inflow data, combining (9) and (11), and considering the flow pattern, the time evolution of permeability $k$ with variable water pressure can be obtained, as displayed in Figure 8.

Permeability increases with time, and concurrently, a higher water pressure corresponds to a higher ultimate permeability and permeability increase amplitude, as is evident from Table 8, for example, ultimate permeability and permeability increase amplitude for $0.2 \mathrm{MPa}$ are $6.1 e-12 \mathrm{~m}^{2}$ and 12.2 , respectively, and that for $0.6 \mathrm{MPa}$ are $1.8 e-11 \mathrm{~m}^{2}$ and 36 , respectively. Meanwhile, the increase in permeability for $p<0.6 \mathrm{MPa}$ is relative smaller, while when pressure increases to $0.6 \mathrm{MPa}$, the permeability increases rapidly and nonlinearly.

It can be observed that the variable of seepage behaviors such as water inflow, Reynolds number, and permeability increased more slowly and that growth is very smaller under low water pressure $(p<0.6 \mathrm{MPa})$, and the flow is a Darcy linear flow. With the increase of water pressure $(p \geq 0.6 \mathrm{MPa})$, the evolution of seepage behaviors increased rapidly, and the flow pattern has changed from a Darcy to a non-Darcy flow, which means that the water inrush risk increases seriously.

Therefore, it is reasonable to conclude that the particle transfer is the key factor determining the porosity, permeability, and water inrush. In addition, when $p \geq 0.6 \mathrm{MPa}$, the mass transfer and porosity, water inflow, and permeability increase rapidly in a short time, indicating that the risk of water inrush is more serious, and it means that the critical pressure of water inrush is $0.6 \mathrm{MPa}$.

\subsection{Effect of Initial Porosity on Seepage-Erosion Properties.} Based on the above test analysis, a critical water pressure $(0.6 \mathrm{MPa})$ of water inrush was obtained for completely weathered granite with initial porosity of 0.36 . Meanwhile, in practical engineering, the pore filling or backfilling is one of the measures to prevent the water inrush. In order to analyze the effect of initial porosity on seepage-erosion properties, and to provide the proposed value for water inrush prevention. Tests are carried out with different initial porosities but with the same water pressure $(0.6 \mathrm{MPa})$; the designed porosities were decreased from 0.36 to critical value by approximately every $16 \%$ of initial porosity $(0.36)$, namely, $0.36,0.3$, and 0.23 critical values.

\subsubsection{Mass Transfer Properties under Different Initial} Porosities. As shown in Figure 9, the mass transfer decreases with the decrease of initial porosity. For $\varphi=0.36$, the maximum mass transfer is $354.22 \mathrm{~g}$, reaching $11 \%$ of the total mass, When $\varphi$ decreases from 0.36 to 0.3 , the maximum mass
TABLE 7: Results of Reynolds number for different water pressures.

\begin{tabular}{lccc}
\hline$p / \mathrm{MPa}$ & $\mathrm{Max}(\mathrm{Re})$ & Time for critical Re/min & Flow pattern \\
\hline 0.2 & 0.10 & - & Darcy \\
0.4 & 3.67 & - & Darcy \\
0.6 & 16.70 & 28 & Darcy, non-Darcy \\
\hline
\end{tabular}

TABLE 8: Results of permeability for different water pressures.

\begin{tabular}{lcccc}
\hline$p / \mathrm{MPa}$ & $\begin{array}{c}\text { Initial } \\
\text { permeability } \\
k_{0}\left(\mathrm{~m}^{2}\right)\end{array}$ & $\begin{array}{c}\text { Ultimate } \\
\text { permeability } \\
k_{\mathrm{f}}\left(\mathrm{m}^{2}\right)\end{array}$ & $\begin{array}{c}\text { Total } \\
\text { time } \\
(\mathrm{min})\end{array}$ & $\begin{array}{c}\text { Permeability } \\
\text { increase } \\
\text { amplitude } k_{\mathrm{f}} / k_{0}\end{array}$ \\
\hline 0.2 & $5.0 e-13$ & $6.1 e-12$ & 40 & 12.2 \\
0.4 & $5.0 e-13$ & $7.1 e-12$ & 76 & 14.2 \\
0.6 & $5.0 e-13$ & $1.8 e-11$ & 66 & 36 \\
\hline
\end{tabular}

TABLE 9: Results of porosity for different initial porosities.

\begin{tabular}{lcccc}
\hline $\begin{array}{l}\text { Initial } \\
\text { porosity } \\
\left(\varphi_{0}\right)\end{array}$ & $\begin{array}{c}\text { Final } \\
\text { porosity } \\
\left(\varphi_{\mathrm{m}}\right)\end{array}$ & $\begin{array}{c}\text { Total } \\
\text { time } \\
t(\mathrm{~min})\end{array}$ & $\begin{array}{c}\text { Porosity } \\
\text { increase } \\
\text { amplitude } \\
\left(\varphi_{\mathrm{m}}-\varphi_{0}\right) / \varphi_{0}\end{array}$ & $\begin{array}{c}\text { Porosity } \\
\text { increase rate } \\
\left(\varphi_{\mathrm{m}}-\varphi_{0}\right) / t\end{array}$ \\
\hline 0.23 & 0.25 & 132 & $8.7 \%$ & $0.015 \%$ \\
0.30 & 0.37 & 146 & $23.3 \%$ & $0.048 \%$ \\
0.36 & 0.44 & 66 & $28.8 \%$ & $0.121 \%$ \\
\hline
\end{tabular}

transfer decreases from $17.3 \%$ to $292.78 \mathrm{~g}$, but still reaching $8.3 \%$ of the total mass; moreover, when $\varphi$ decreases to 0.23 , the maximum mass transfer decreases from $65.7 \%$ to $121.4 \mathrm{~g}$, only reaching $3.1 \%$ of the total mass. This indicates that the decrease of initial porosity is an effect measure to restrain the mass transfer and water inrush risk, especially when the porosity decreases over $30 \%$ of the undisturbed soil.

With the decrease of initial porosity, the porosity increase amplitude and rate of finial porosity decrease, and the total evolution time extends in general, as shown in Figure 10 and Table 9. For example, the evolution time, the porosity increase amplitude, and increase rate for 0.36 are $66 \mathrm{~min}$, $28.8 \%$, and $0.12 \% / \mathrm{min}$, respectively, in comparison, while when $\varphi=0.23$, the evolution time extends to $132 \mathrm{~min}$, twice longer than that in $\varphi=0.36$, and the porosity increase amplitude and increase rate are $8.7 \%$ and $0.015 \% / \mathrm{min}$, respectively, a $70 \%$ and $87.5 \%$ decrease of that in $\varphi=0.36$, respectively. This is mainly because that the sample with lower porosity has a higher compactness, a lower permeability, and a smaller flow channels.

3.2.2. Seepage Properties under Different Initial Porosities. As displayed in Figure 11, water inflow decreases with the decrease of initial porosity, for example, water inflow for $\varphi=0.36$ is $395.84 \mathrm{ml} / \mathrm{min}$, and the evolution curve is nonlinear, while when $\varphi \leq 0.3$, the evolution curve is kept stable and almost unchanged; the finial water inflow is less than $100 \mathrm{ml} / \mathrm{min}$, an over $60 \%$ decrease of that in $\varphi=0.36$, 
TABLE 10: Results of permeability for different initial porosities.

\begin{tabular}{lccc}
\hline $\begin{array}{l}\text { Initial } \\
\text { porosity } \\
\left(\varphi_{0}\right)\end{array}$ & $\begin{array}{c}\text { Initial } \\
\text { permeability } \\
k_{0}\left(\mathrm{~m}^{2}\right)\end{array}$ & $\begin{array}{c}\text { Ultimate } \\
\text { permeability } \\
k_{\mathrm{f}}\left(\mathrm{m}^{2}\right)\end{array}$ & $\begin{array}{c}\text { Permeability } \\
\text { increase } \\
\text { amplitude } k_{\mathrm{f}} / k_{0}\end{array}$ \\
\hline 0.23 & $3.1 e-13$ & $3.7 e-12$ & 12 \\
0.30 & $3.9 e-13$ & $4.9 e-12$ & 13 \\
0.36 & $5.0 e-13$ & $1.8 e-11$ & 36 \\
\hline
\end{tabular}

indicating that the water inflow decreases rapidly when the initial porosity decreases to 0.3 , especially it decreases $30 \%$ to 0.23 .

Figure 12 shows the time evolution of the Reynolds number $(\mathrm{Re})$ to variable initial porosity. It can be observed from the figure that Re increases rapidly and nonlinearly, exceeding the critical Reynolds number in $28 \mathrm{~min}$ when $\varphi=0.36$, indicating that the flow is a non-Darcy flow. However, with the initial porosity decrease, the maximum Re decreases to 4.17; particularly for 0.23 , the maximum Re is only 0.165 , which is much less than 10 , and in the entire time, Re is linearly evolving, indicating that the flow has changed from a non-Darcy to a Darcy flow.

Figure 13 shows the time evolution of permeability $k$ with variable initial porosity. Permeability increases with time, and concurrently, a lower initial porosity corresponds to a lower ultimate permeability and permeability increase amplitude, as is evident from Table 10, for example, the ultimate permeability and permeability increase amplitude for $\varphi=0.36$ are $1.8 e-11 \mathrm{~m}^{2}$ and 36 , respectively; however, for $\varphi=0.23$, the ultimate permeability is $3.7 e-12 \mathrm{~m}^{2}$, an $80 \%$ decrease of that in $\varphi=0.36$, and the permeability increase amplitude is 12 , a $67 \%$ decrease of that in $\varphi=0.36$. This indicates that the permeability evolution can be effectively restrained when the initial porosity decreases to 0.3 below, particularly for $\varphi=0.23$.

Based on the above analysis of the mass transfer, porosity, and flow properties under different initial porosities, it is reasonable to conclude that the pore filling or backfilling is an effective measure to ameliorate the anti-inrush properties for completely weathered granite. In addition, when the porosity decreases $30 \%$ of initial porosity to 0.23 , the ultimate mass transfer, water inflow, and permeability decrease $65.7 \%$, $60 \%$, and $80 \%$, respectively, indicating that the risk of water inrush was reduced significantly, and it means that the critical porosity of anti-inrush in completely weathered granite is 0.23 .

\section{Conclusions}

A self-designed apparatus was developed to investigate the evolution features of water inrush in completely weathered granite, and a series of tests were carried out to study the effects of water pressure and porosity on seepage-erosion properties. The main findings were as follows:

(1) The particle transfer could cause an increase in the porosity, permeability, and water inflow and eventually induce a water inrush disaster. Meanwhile, the flow pattern may be changed with the mass transfer; at the beginning, the flow is a Darcy flow; however, with the continuous particle transfer, the flow may be transferred into a nonlinear flow, leading a rapidly increase of permeability and water inflow, which is a significant signal for water inrush.

(2) A series of tests were designed to investigate the effects of the water pressure on water inrush evolution, and a critical value $(p=0.6 \mathrm{MPa})$ that caused the water inrush was obtained. In particular, when the water pressure increased to the critical value, the values of water inflow and permeability reached $395.8 \mathrm{ml} / \mathrm{min}$ and $1.8 e-11 \mathrm{~m}^{2}$, respectively, both thrice larger than that at a lower water pressure $(p \leq 0.4 \mathrm{MPa})$, and the flow changed from a Darcy flow to a significant nonlinear flow.

(3) Based on the tests under different water pressures, tests with variable porosities were carried out to study the initial porosity on the water inrush evolution, and a critical value $(\varphi=0.23)$ to control the water inrush was observed. In particular, when the initial porosity decreases to the critical value, the values of water inflow and permeability both decrease $80 \%$ of that in undisturbed stratum $(\varphi=0.36)$, and the flow pattern has changed from a nonlinear flow to a Darcy flow, indicating that the water inrush risk has been restrained and the pore filling or backfilling technology is an effective measure to prevent water inrush.

\section{Data Availability}

The data used to support the findings of this study are available from the corresponding author upon request.

\section{Conflicts of Interest}

The authors declare that they have no conflicts of interest.

\section{Acknowledgments}

This work was supported by the China National Basic Research Program, the "973 Program" (no. 2013CB036006), and the China National Natural Science Foundation (nos. 51509246 and 51708220). These financial supports are gratefully acknowledged.

\section{References}

[1] Q. L. Cui, H. N. Wu, S. L. Shen, Z. Y. Yin, and S. Horpibulsuk, "Protection of neighbour buildings due to construction of shield tunnel in mixed ground with sand over weathered granite," Environment and Earth Science, vol. 75, no. 6, p. 458, 2016.

[2] J. Liu, W. Chen, D. Yang, J. Yuan, X. Li, and Q. Zhang, "Nonlinear seepage-erosion coupled water inrush model for completely weathered granite," Marine Georesources \& Geotechnology, vol. 36, no. 4, pp. 484-493, 2017.

[3] B. Yao, Z. Chen, J. Wei, T. Bai, and S. Liu, "Predicting erosioninduced water inrush of karst collapse pillars using inverse 
velocity theory," Geofluids, vol. 2018, Article ID 2090584, 18 pages, 2018.

[4] K. Zhang, B. Zhang, J. Liu, D. Ma, and H. Bai, "Experiment on seepage property and sand inrush criterion for granular rock mass," Geofluids, vol. 2017, Article ID 9352618, 10 pages, 2017.

[5] D. L. Zhang, Q. Fang, and H. C. Lou, "Grouting techniques for the unfavorable geological conditions of Xiang'an subsea tunnel in China," Journal of Rock Mechanics and Geotechnical Engineering, vol. 6, no. 5, pp. 438-446, 2014.

[6] S. L. Shen and Y. S. Xu, "Numerical evaluation of land subsidence induced by groundwater pumping in Shanghai," Canadian Geotechnical Journal, vol. 48, no. 9, pp. 13781392, 2011.

[7] S. L. Shen, Y. X. Wu, and A. Misra, "Calculation of head difference at two sides of a cut-off barrier during excavation dewatering," Computers and Geotechnics, vol. 91, pp. 192202, 2017.

[8] Y. Zhao, P. Li, and S. Tian, "Prevention and treatment technologies of railway tunnel water inrush and mud gushing in China," Journal of Rock Mechanics and Geotechnical Engineering, vol. 5, no. 6, pp. 468-477, 2013.

[9] H. M. Lyu, W. J. Sun, S. L. Shen, and A. Arulrajah, "Flood risk assessment in metro systems of mega-cities using a GIS-based modeling approach," Science of the Total Environment, vol. 626, pp. 1012-1025, 2018.

[10] F. Arıkan, R. Ulusay, and N. Aydın, "Characterization of weathered acidic volcanic rocks and a weathering classification based on a rating system," Bulletin of Engineering Geology and the Environment, vol. 66, no. 4, pp. 415-430, 2007.

[11] T. I. Gamon, "A comparison of existing schemes for the engineering description and classification of weathered rocks in Hong Kong," Bulletin of the International Association of Engineering Geology, vol. 28, no. 1, pp. 225-232, 1983.

[12] T. Y. Irfan, "Mineralogy, fabric properties and classification of weathered granites in Hong Kong," Quarterly Journal of Engineering Geology and Hydrogeology, vol. 29, no. 1, pp. 5-35, 1996.

[13] S. Ceryan, S. Tudes, and N. Ceryan, "A new quantitative weathering classification for igneous rocks," Environmental Geology, vol. 55, no. 6, pp. 1319-1336, 2008.

[14] J. N. Shirlaw, "Pressurised TBM tunnelling in mixed face conditions resulting from tropical weathering of igneous rock," Tunnelling and Underground Space Technology, vol. 57, pp. 225-240, 2016.

[15] J. N. Shirlaw, S. R. Hencher, and J. Zhao, "Design and construction issues for excavation and tunnelling in some tropically weathered rocks and soils," in International Society for Rock Mechanics International Symposium, Melbourne, Australia, 2000.

[16] J. Liu, W. Chen, J. Yuan, C. Li, Q. Zhang, and X. Li, “Groundwater control and curtain grouting for tunnel construction in completely weathered granite," Bulletin of Engineering Geology and the Environment, vol. 77, no. 2, pp. 515-531, 2018.

[17] W. J. Guo and Y. X. Liu, "The concept of water in-rush coefficient and its application," Journal of Hebei Coal, vol. 2, pp. 56-60, 1989.

[18] Y. X. Wu, J. S. Shen, W. C. Cheng, and T. Hino, "Semianalytical solution to pumping test data with barrier, wellbore storage, and partial penetration effects," Engineering Geology, vol. 226, pp. 44-51, 2017.
[19] L. J. Li, Study of Water In-Rush Mechanism, Ph.D. Thesis, China University of Mining and Geology, Xuzou, Peoples's Republic of China, 1996.

[20] D. Ma, "Boundary integral computation of elastic water resisting key strata under the condition of discontinuous load," Computer Modeling in Engineering and Sciences, vol. 83, pp. 561-574, 2012.

[21] J. A. Wang and H. D. Park, "Coal mining above a confined aquifer," International Journal of Rock Mechanics and Mining Sciences, vol. 40, no. 4, pp. 537-551, 2003.

[22] T. Yang, C. Tang, and H. Liu, "Numerical model of the instability-failure process of the coal-bed floor due to confined water inrush," Journal of Geomechanics, vol. 9, pp. 281288, 2003.

[23] T. H. Yang, J. Liu, W. C. Zhu, D. Elsworth, L. G. Tham, and C. A. Tang, "A coupled flow-stress-damage model for groundwater outbursts from an underlying aquifer into mining excavations," International Journal of Rock Mechanics and Mining Sciences, vol. 44, no. 1, pp. 87-97, 2007.

[24] X. X. Liu, S. L. Shen, Y. S. Xu, and Z. Y. Yin, “Analytical approach for time-dependent groundwater inflow into shield tunnel face in confined aquifer," International Journal for Numerical and Analytical Methods in Geomechanics, vol. 42, no. 4, pp. 655-673, 2018.

[25] H. Liu, T. H. Yang, Q. L. Yu, S. K. Chen, and C. H. Wei, "Numerical analysis on the process of water inrush from the floor of seam 12 in Fangezhuang coal mine," Coal Geology \& Exploration, vol. 38, no. 3, pp. 27-31, 2010.

[26] D. Ma, X. X. Miao, Z. Q. Chen, and X. B. Mao, "Experimental investigation of seepage properties of fractured rocks under different confining pressures," Rock Mechanics and Rock Engineering, vol. 46, no. 5, pp. 1135-1144, 2013.

[27] Z. P. Meng, B. B. Zhang, X. T. Xie, Z. W. Shen, F. J. He, and Z. D. Pan, "Evaluation of water inrush risk of seam floor based on lithology-structure," Coal Geology \& Exploration, vol. 39, no. 5, pp. 35-40, 2011.

[28] J. B. Walsh, "Effect of pore pressure and confining pressure on fracture permeability," International Journal of Rock Mechanics and Mining Sciences \& Geomechanics Abstracts, vol. 18, no. 5, pp. 429-435, 1981.

[29] L. Wang, Z. Chen, H. Kong, and H. Shen, "Effects of pore pressure on permeability of sandstone during bending deformation," International Journal of Rock Mechanics and Mining Sciences, vol. 70, pp. 26-32, 2014.

[30] F. Geng and J. H. Saleh, "Challenging the emerging narrative: critical examination of coalmining safety in China, and recommendations for tackling mining hazards," Safety Science, vol. 75, pp. 36-48, 2015.

[31] P. Erhard, D. Etling, U. Muller, U. Riedel, K. R. Sreenivasan, and J. Warnatz, Prandtl-Essentials of Fluid Mechanics, Springer Science \& Business Media, New York, NY, USA, 3rd edition, 2009.

[32] X. Y. Kong, Advanced Mechanics of Fluids in Porous Media, Press of University of Science and Technology of China, Hefei, China, 2nd edition, 2010.

[33] P. Forchheimer, "Wasserbewegung durch boden," Zeitschrift des Vereins Deutscher Ingenieure, vol. 45, pp. 1782-1788, 1901. 

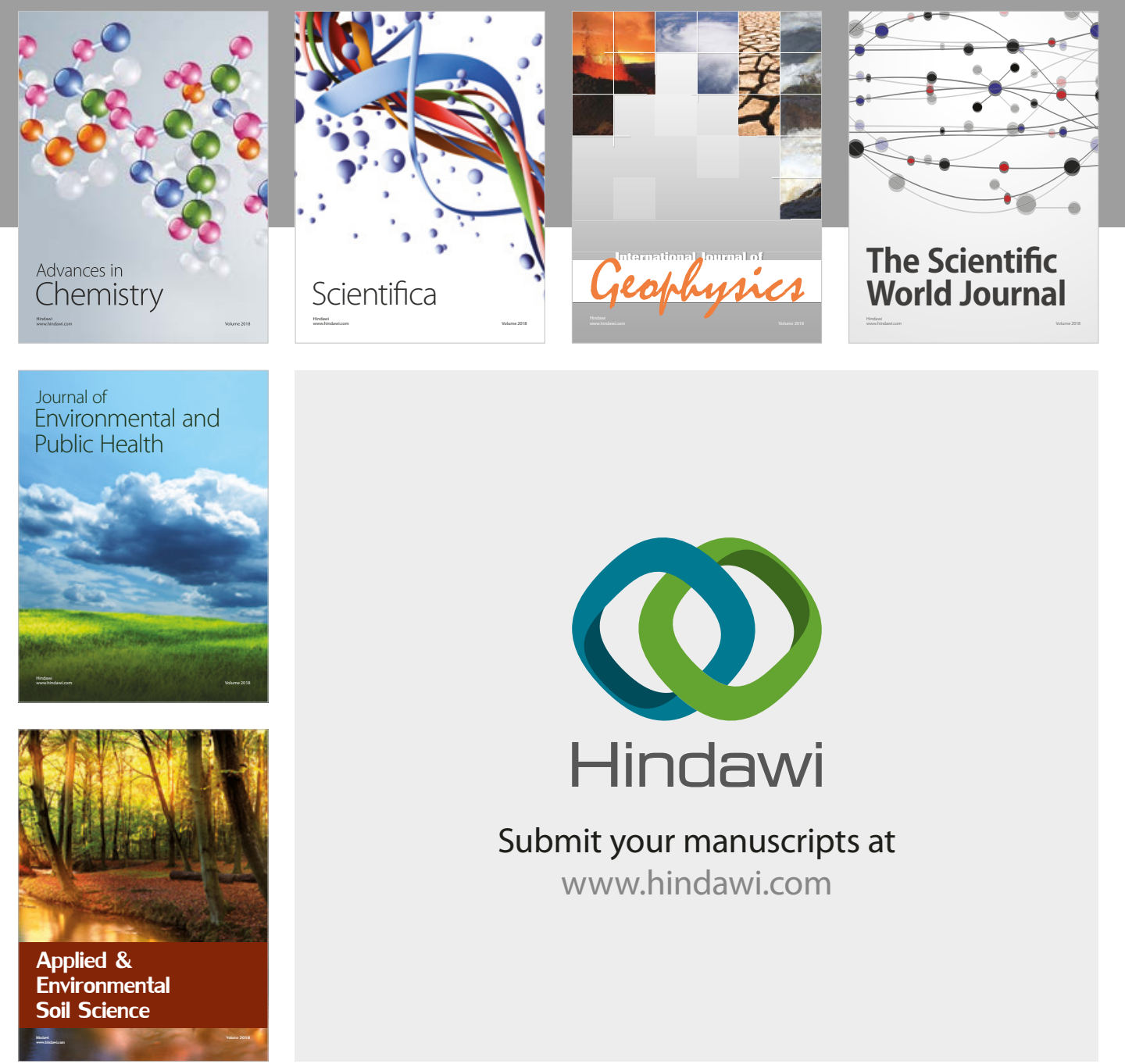

The Scientific

\section{World Journal}
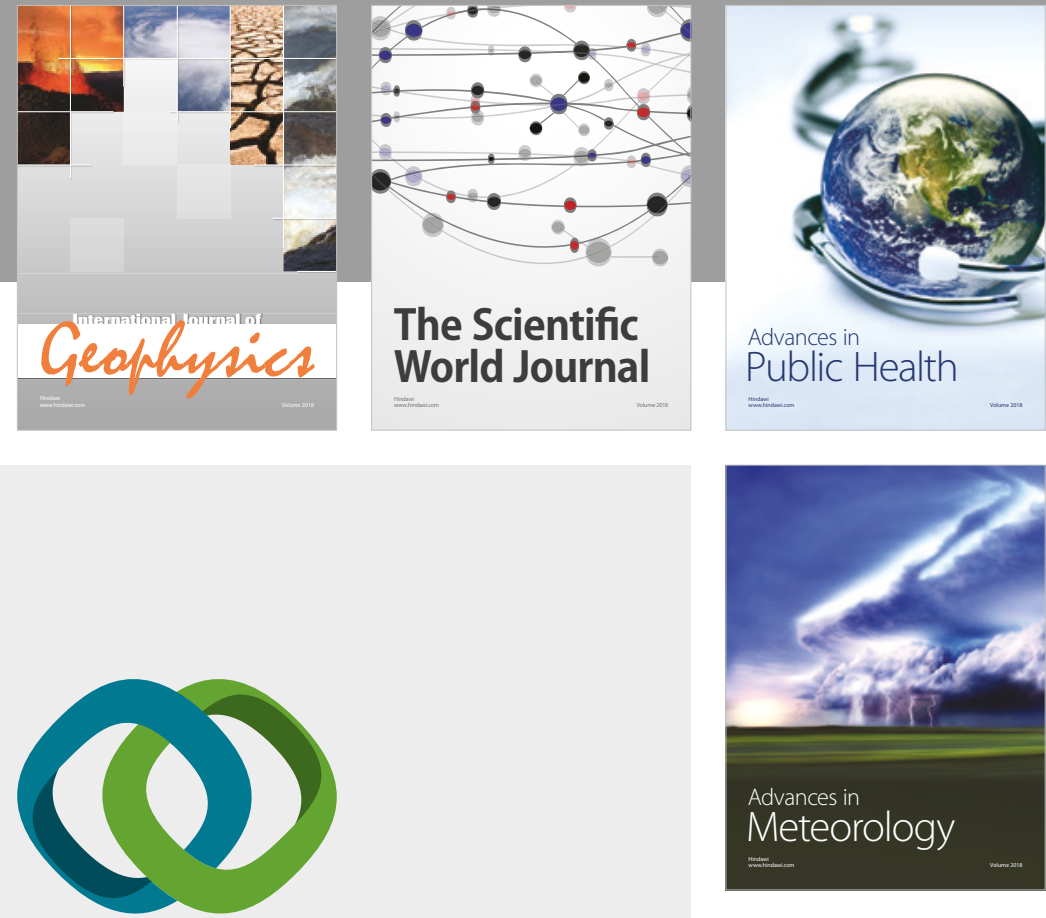

Advan

Public Health

\section{Hindawi}

Submit your manuscripts at

www.hindawi.com
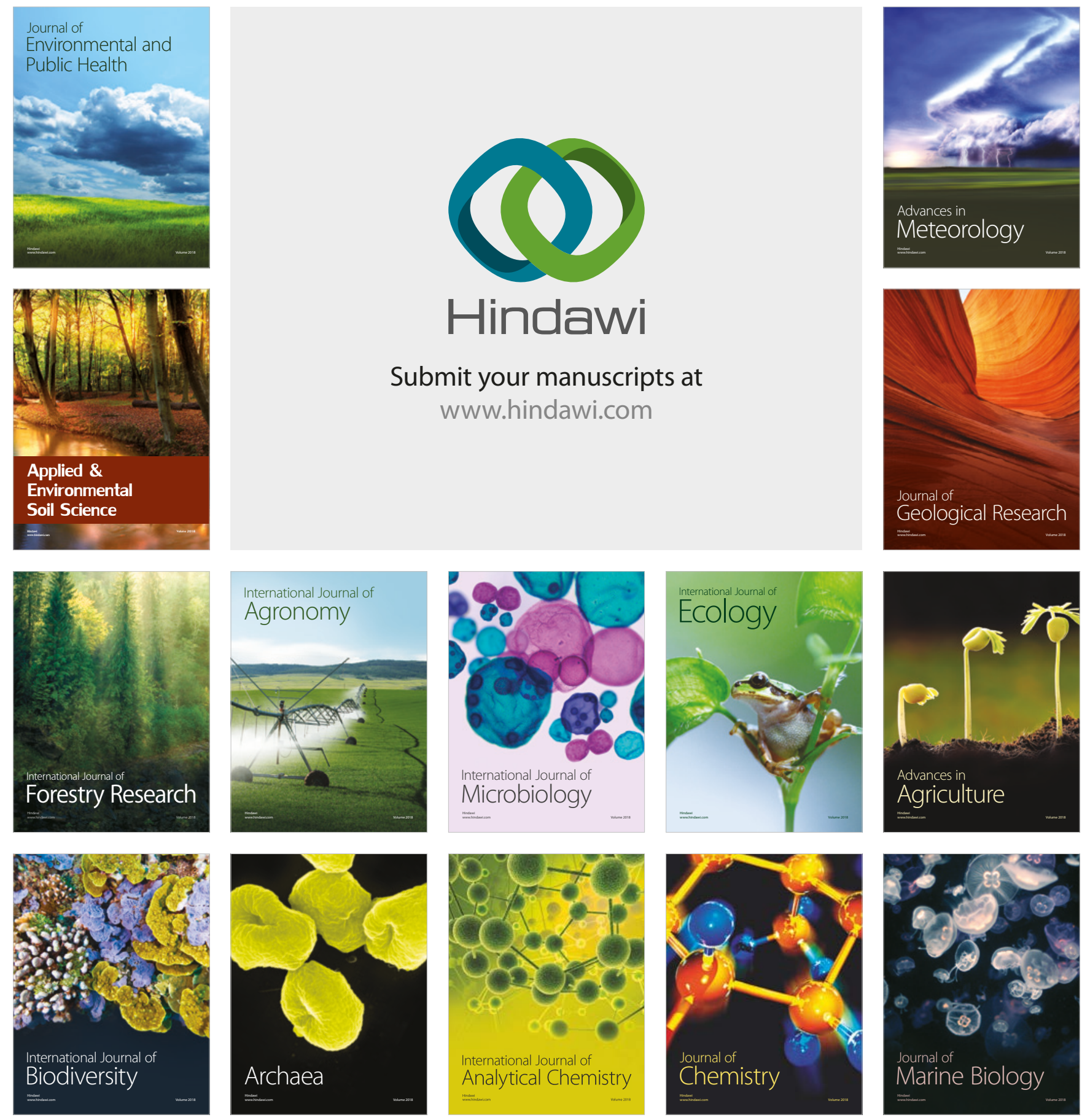